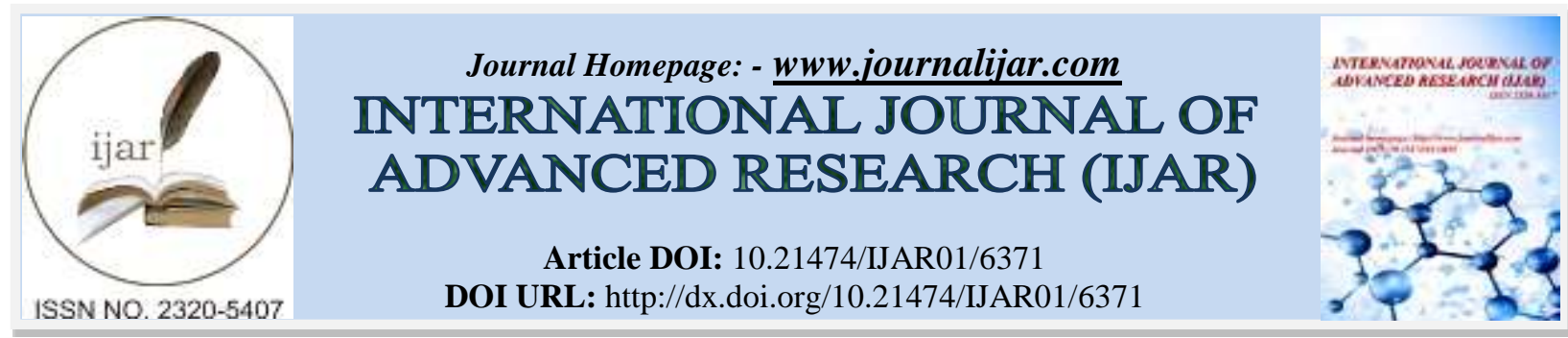

RESEARCH ARTICLE

\title{
PVP AND BKP STILL THE SAFEST AND EFFECTIVE METHOD OF TREATMENT OF OCFS FOR SHORT AND LONG TERM MANAGEMENT-A REVIEW.
}

\section{Suman Rouniyar, Gao-Jun Teng, Liu Jiacheng, Govind P.Gupta, Ramhari Rouniyar, Dip Sunder and Munezero Champion.}

\section{Manuscript Info}

Manuscript History

Received: 21 November 2017

Final Accepted: 23 December 2017

Published: January 2018

Key words:-

PVP, BKP, VCFs, OCFs.
Abstract

PVP and BKP are the vertebral augmentation procedures which are being used during the last 2 decades for the treatment of osteoporotic vertebral fractures and tumor associated fractures. Osteoporosis is one of the leading causes of mortality and morbidity in old age leading to the deterioration of physical and mental function. About Two hundred million women are affected by osteoporosis globally. The bone may be weakened to such a degree that a break may occur with minor stress or spontaneously without showing typical symptoms. The long duration of conservative therapy or open surgery method would not be suitable for older patient with various co-morbidity. After the invention of treatment of PVP and BKP, it brought a turning point in the history of treatment of OCFs. PVP and BKP were limited to VCFs and haemangiomas before, but the indication of these treatments have expanded to include metastatic vertebral cancer and multiple myeloma. Even some contraindication like vertebral plana, severe vertebral fracture, spinal canal compromise due to repulsed fragments were considered as a treatment of choice .PVP and BKP treatment showed immediate postoperative pain relief and improvement in quality of life .PVP takes less duration of time during procedure and is cost effective with BKP being superior in restoration of vertebral height and decrease in cement leakage. Various new methods have gained popularity in recent years but due to the lack of various adverse effects as proven in different study and high treatment cost still make them doubtful. The review consist of brief history of the development of PVP and BKP techniques, their clinical outcome, little briefing of newer ongoing methods and future research about the safety and efficacy of the procedures in treatment of OCFs.

Copy Right, IJAR, 2018,. All rights reserved.

\section{Introduction:-}

As we know, osteoporotic vertebral compression fracture is one of the most common fractures affecting old age population especially in women. . About Two hundred million women are affected by osteoporosis globally. OVCs symptoms lead to deteriorated physical function, psychosocial ability, quality of life and social isolation[14].Worsening of the pain which may be acute, chronic, excruciating or persistent is the principle manifestation of most of the OCVs. As open surgery for these old patients with multiple medical co morbidities would lead to increased mortality, conservative therapy is considered as the first treatment of choice which include bed rest, 
analgesic and external bracing but due to adverse effect of long term conservative therapy like pneumonia, decubitus ulcers, thromboembolism and development of new vertebral fractures which lead to morbidity and mortality. So there was a need of such treatment which is less invasive and can be used for long period with minimum adverse effect. The introduction of PVP and BKP which were more effective and less expensive than conservative therapy and open surgery brought a miraculous benefit to the patient suffering from OCFs.

\section{PVP and BKP:-}

PVP and BKP are the 2 vertebral augmentation procedures which are being used during the last 2 decades; VCF may either be osteoporotic or tumor-associated. A milestone change bought by Pierre Galibert and Herve Deramond (interventional neuroradiologists in Amiens, France) in 1987 in treatment of haemangiomas by percutaneous vertebroplasty is thought to be significant in medical history[5]. PVP is a therapeutic and interventional radiologic procedure with minimally invasive image guided therapy that involves the injection of bone cement PMMA (Polymethylmethacrylate) into a cervical, thoracic or lumber vertebral bone lesion for the relieve of pain and strengthening of bone. [6] It provides significant pain relief with the potential for improving functional outcome. Later, balloon kyphoplasty (BKP), the modification of PVP was introduced by Dr. Mark Reiley, an orthopedic surgeon in 1998 and forwarded by Belkoff in 2001.BKP involves the percutaneous inflatable balloon device placement into a vertebral body.[7, 8]

\section{Pain relief mechanism:-}

PVP and BKP has been used in the treatment of lytic lesions like osteoporotic or malignant fractures due to metastasis, aggressive haemangiomas and multiple myeloma.Although the original volume of vertebra is not retained to its previous form, and it helps to maintain its compressive force to some extent preventing further degradation. After the bone cement (PMMA) is injected into vertebra, it hinders the micro motions of vertebral fracture fragments thus promoting realignment and reducing stimulations of intraosseous and periosteal nerve endings.[9] Also, bone nerve endings are destroyed by exothermal and cytotoxic action during cement polymerization. . 110] This phenomenon could be the reason for immediate relief of pain in most of the patients. This process is done under the fluoroscopic and CT guidance so that it gives us proper guidance during the whole treatment procedure.

\section{Indications and Contraindications:-}

PVP and BKP treatment is used only when conservative treatment fails. According to newer guidelines of ACRASNR-ASSR-SIR-SNIS PRACTICE PARAMETER FOR THE PERFORMANCE OF VERTEBRAL AUGMENTATION 2017, Indication includes Painful osteoporotic vertebral fracture(s) refractory to medical therapy, Vertebral bodies weakened by neoplasm and Symptomatic vertebral body micro fracture (as documented by magnetic resonance imaging [MRI] or nuclear imaging, and/or lytic lesion seen on computed tomography [CT]) without obvious loss of vertebral body height. Absolute Contraindications includes Septicemia, Active osteomyelitis of the target vertebra, Uncorrectable coagulopathy, Allergy to bone cement or opacification agent, along with some relative contraindication. It was limited to lytic tumors and OCFs before but due to development of new techniques and methods this treatment has extended as the treatment of choice for many vertebral fractures.[11-18]Even some contraindication of this treatment has been used as a treatment of choice. For example vertebral plana, severe vertebral fracture, spinal canal compromise due to repulsed fragments were considered as the contraindications of PVP and BKP but according to the studies[19-24] it shows that it can be taken as the treatment of choice for these conditions. In all these patients the treatment brought a significant improvement with better functional outcome.

\section{Complication:-}

Complications following this treatment include pulmonary embolism, fracture adjacent to treated vertebra, back pain, rib fracture, pneumothorax from punctured lung, transient arterial hypotension, infection, bleeding, fever, optic neuritis and various neurological complications $[8,25]$. The most common complication include cement leakage and fracture adjacent to treated vertebra .So many studies have been published on this issue and most of them elaborated that cement leakage is less common in BKP.This could be explained that cancellous bone is compressed into a tight form creating a cavity by inflatable balloon during BKP, so the cement which is in the higher viscous form as compared to PVP is injected into the cavity with less injection pressure. This process contradicts PVP in which under high injection pressure, the low ratio of cement viscosity to spongiosa viscosity causes the cement which is injected to fill the gaps of fracture vertebra more easier to leak into blood vessels and near cortex $[10,26]$ Cement leakage are mostly into epidural fat, the perivertebral soft tissue, epidural veins, perivertebral vein (leading to pulmonary embolism) and foramina vein. According to many studies pulmonary embolism occurs in a lot of the 
cases but most of them remain asymptomatic[8-10, 20, 27-29].Many study proved that the incidence of cement leakage is more during PVP than BKP.

The other most common complication include increased incidence of vertebral fracture adjacent to the treated vertebra as compared to non adjacent vertebra. It has been reported that the rate of developing new VCFs after initial VCFs is 4 times greater than in people without initial VCFs.[10, 30, 31] Due to the compressive force of the bone cement used (PMMA) (100 MPa) which is lower than cortical bone (175 MPa) and higher than trabecullar bone (3MPa), there is transfer of greater load after cement augmentation to the adjacent vertebral bodies so the treated vertebra produces a stress riser effect and these increased stresses are transferred to intervertebral discs and to the adjacent vertebras. Also due to increase in kyphotic angle, the compressive force at the injected cement, the treated vertebral body and the surrounding vertebral bodies is accelerated. This could also be the reason for the increased incidence of adjacent vertebral body fracture. Many studies proved that PVP increases the incidence of the fracture of adjacent vertebra than nonadjacent one as compared to BKP [8, 10, 20, 28, 32].

In BKP, the vertebral height can be maintained for longer duration compared to PVP .Also the postoperative improvement of kyphotic angle is seen in BKP and it could be maintained for longer duration with slight loss of correction to the angle of kyphosis as compared to PVP. The improvement of kyphotic angle in BKP is due to the cavity created by inflatable balloon which allows more cement injection and helps to maintain kyphotic angle. The other reason could partially be attributed to the prone positioning of the patient during operation and subsidence of the 2 endplates of the fractured vertebra.[10]. With the improvement of kyphotic angle, the patient posture can be regained and also it improves pulmonary function and increases survival rate of the patient. So the patient with severe kyphotic deformity or severe OCFs should be considered for BKP treatment.

\section{Other Methods:-}

Other modified newer technique such as radiofrequency kyphoplasty showed superior in pain reduction than PVP and BKP in some studies. Radiofrequency kyphoplasty or Radiofrequency targeted vertebral augmentation (RFTVA) is a method in which PMMA cement is applied in a controlled and targeted fashion preventing the destruction of remaining microstructure of the vertebra. This process is facilitated because the PMMA cement is converted in ex-vivo with the help of radiofrequency resulting into a semisolid mass which retains a constant, very high viscosity for about 30mins. This allows increase working time for physician helping consistent flow of ultrahigh viscous cement without premature hardening. Also due to its shorter surgery duration and its indication for some of the OCFs which has been contraindicated for PVP and BKP, this process is evolving in recent years. But it has not yet been proved superior to PVP and BKP [8, 33,34]. Supplement implants system have also gained popularity in recent year. These are designed to optimize stabilization through supplement implants along with the bone cement. The supplement implant and Kiva system showed decrease in cement leakage and decrease in frequency of adjacent vertebral fracture after treatment $[8,35]$. Vertebral body stent is the vertebral augmentation technique in which a metal stent is introduced extrapedicularly or transpedicularly into the vertebra and unfolded there along with balloon. Some study mentions vertebral body stent method which helps in restoration of vertebral body height $[8$, 36]. Future research should focus on the design and development of materials and techniques to minimize the associated complications, maximize efficacy and safety, and broaden the area of implementation. From the above discussion, we find that PVP and KVP are still the treatment of choice for OCFs in immediate postoperative pain reduction with PVP using less time for operation and being cost effective. On the other hand, BKP helps in long term pain relief, restoration of vertebral height and decreased incidence of cement leakage.[37-51]

\section{Conclusion:-}

PVP and BKP both are effective in vertebral augmentation and pain-relief in patients with osteoporotic or tumorassociated VCFs in short and long term management. PVP and BKP both give immediate pain relief and improvement in physical function. The complication rate in both procedures is considered overall low. The rate of cement leakage is high in PVP being most of them asymptomatic. On the other hand BKP is superior in terms of restoration of vertebral body height. The newer technique radiofrequency kyphoplasty and vertebral body stent shows promising result in decrease cement leakage and height restoration in some studies but in order to establish the relative benefits over PVP and BKP well designated randomized clinical trials are require to be conducted. Nevertheless more study is required with more advanced technology to solve the present drawbacks of the existing procedures and evolve with new methods which further proves its efficacy and improved safety with less adverse effect and minimum cost. 


\section{References:-}

1. Liu, J.T., et al., Long-term follow-up study of osteoporotic vertebral compression fracture treated using balloon kyphoplasty and vertebroplasty. J Neurosurg Spine, 2015. 23(1): p. 94-8.

2. Masala, S., et al., Percutaneous vertebroplasty in the management of vertebral osteoporotic fractures. Shortterm, mid-term and long-term follow-up of 285 patients. Skeletal Radiol, 2009. 38(9): p. 863-9.

3. Peh, W.C., L.A. Gilula, and D.D. Peck, Percutaneous vertebroplasty for severe osteoporotic vertebral body compression fractures. Radiology, 2002. 223(1): p. 121-6.

4. McKiernan, F., R. Jensen, and T. Faciszewski, The dynamic mobility of vertebral compression fractures. J Bone Miner Res, 2003. 18(1): p. 24-9.

5. Deramond, H., et al., Percutaneous vertebroplasty with polymethylmethacrylate. Technique, indications, and results. Radiol Clin North Am, 1998. 36(3): p. 533-46.

6. Hadjipavlou, A.G., et al., Percutaneous vertebroplasty and balloon kyphoplasty for the treatment of osteoporotic vertebral compression fractures and osteolytic tumours. Journal of Bone \&amp;amp; Joint Surgery, British Volume, 2005. 87-B(12): p. 1595.

7. Belkoff, S.M., et al., An ex vivo biomechanical evaluation of an inflatable bone tamp used in the treatment of compression fracture. Spine (Phila Pa 1976), 2001. 26(2): p. 151-6.

8. Bornemann, R., et al., Treatment options for vertebral fractures an overview of different philosophies and techniques for vertebral augmentation. Eur J Orthop Surg Traumatol, 2014. 24 Suppl 1: p. S131-43.

9. Barbero, S., et al., Percutaneous vertebroplasty: the follow-up. La radiologia medica, 2008. 113(1): p. 101-113.

10. Wang, H., et al., Comparison of Percutaneous Vertebroplasty and Balloon Kyphoplasty for the Treatment of Single Level Vertebral Compression Fractures: A Meta-analysis of the Literature. Pain Physician, 2015. 18(3): p. 209-22.

11. Lee, J.H., J.-H. Lee, and Y. Jin, Surgical techniques and clinical evidence of vertebroplasty and kyphoplasty for osteoporotic vertebral fractures. Vol. 3. 2017.

12. Berenson, J., et al., Balloon kyphoplasty versus non-surgical fracture management for treatment of painful vertebral body compression fractures in patients with cancer: a multicentre, randomised controlled trial. The Lancet Oncology, 2011. 12(3): p. 225-235.

13. Fourney, D.R., et al., Percutaneous vertebroplasty and kyphoplasty for painful vertebral body fractures in cancer patients. J Neurosurg, 2003. 98(1 Suppl): p. 21-30.

14. Majd, M.E., S. Farley, and R.T. Holt, Preliminary outcomes and efficacy of the first 360 consecutive kyphoplasties for the treatment of painful osteoporotic vertebral compression fractures. Spine J, 2005. 5(3): p. 244-55.

15. Lieberman, I.H., et al., Initial outcome and efficacy of "kyphoplasty" in the treatment of painful osteoporotic vertebral compression fractures. Spine (Phila Pa 1976), 2001. 26(14): p. 1631-8.

16. Lemke, D.M., Vertebroplasty and kyphoplasty for treatment of painful osteoporotic compression fractures. J Am Acad Nurse Pract, 2005. 17(7): p. 268-76.

17. Chen, G., et al., Percutaneous kyphoplasty in the treatment of painful osteoblastic metastatic spinal lesions. Journal of Clinical Neuroscience, 2013. 20(7): p. 948-950.

18. Wang, Y., et al., Clinical evaluation of percutaneous kyphoplasty in the treatment of osteolytic and osteoblastic metastatic vertebral lesions. International Journal of Surgery, 2016. 30(Supplement C): p. 161-165.

19. Pedicelli, A., et al., Vertebra plana: reappraisal of a contraindication to percutaneous vertebroplasty. Eur $\mathbf{J}$ Radiol, 2013. 82(12): p. 2303-8.

20. Sigaux, J., et al., Efficacity and feasibility of vertebroplasty for severe vertebral fracture: a retrospective study of 12 vertebroplasties. Joint Bone Spine, 2013. 80(3): p. 328-31.

21. Hiwatashi, A. and P.L. Westesson, Vertebroplasty for osteoporotic fractures with spinal canal compromise. AJNR Am J Neuroradiol, 2007. 28(4): p. 690-2.

22. Chen, J.F. and S.T. Lee, Percutaneous vertebroplasty for treatment of thoracolumbar spine bursting fracture. Surg Neurol, 2004. 62(6): p. 494-500; discussion 500.

23. Amoretti, N., et al., Burst fracture of the spine involving vertebrae presenting no other lesions: the role of vertebroplasty. Clin Imaging, 2005. 29(6): p. 379-82.

24. Appel, N.B. and L.A. Gilula, Percutaneous vertebroplasty in patients with spinal canal compromise. AJR Am J Roentgenol, 2004. 182(4): p. 947-51.

25. Zhang, J.D., et al., Comparison of vertebroplasty and kyphoplasty for complications. Orthop Surg, 2011. 3(3): p. $158-60$.

26. He, S.C., et al., Percutaneous Vertebroplasty for Symptomatic Schmorl's Nodes: 11 Cases with Long-term Follow-up and a Literature Review. Pain Physician, 2017. 20(2): p. 69-76. 
27. Kim, J.H., S.H. Yoo, and J.H. Kim, Long-term Follow-up of Percutaneous Vertebroplasty in Osteoporotic Compression Fracture: Minimum of 5 Years Follow-up. Asian Spine J, 2012. 6(1): p. 6-14.

28. Tanigawa, N., et al., Percutaneous vertebroplasty for osteoporotic compression fractures: long-term evaluation of the technical and clinical outcomes. AJR Am J Roentgenol, 2011. 196(6): p. 1415-8.

29. Do, H.M., et al., Prospective analysis of clinical outcomes after percutaneous vertebroplasty for painful osteoporotic vertebral body fractures. AJNR Am J Neuroradiol, 2005. 26(7): p. 1623-8.

30. Klotzbuecher, C.M., et al., Patients with prior fractures have an increased risk of future fractures: a summary of the literature and statistical synthesis. J Bone Miner Res, 2000. 15(4): p. 721-39.

31. Lindsay, R., et al., Risk of new vertebral fracture in the year following a fracture. Jama, 2001. 285(3): p. 320-3.

32. Eck, J.C., et al., Comparison of vertebroplasty and balloon kyphoplasty for treatment of vertebral compression fractures: a meta-analysis of the literature. Spine J, 2008. 8(3): p. 488-97.

33. Rollinghoff, M., et al., Is there a stable vertebral height restoration with the new radiofrequency kyphoplasty? A clinical and radiological study. Eur J Orthop Surg Traumatol, 2013. 23(5): p. 507-13.

34. Mattyasovszky, S.G., et al., [Minimally invasive cement augmentation of osteoporotic vertebral compression fractures with the new radiofrequency kyphoplasty]. Oper Orthop Traumatol, 2014. 26(5): p. 497-512.

35. Korovessis, P., et al., Initial clinical experience with a novel vertebral augmentation system for treatment of symptomatic vertebral compression fractures: a case series of 26 consecutive patients. BMC Musculoskelet Disord, 2011. 12: p. 206.

36. Rotter, R., et al., Vertebral body stenting: a new method for vertebral augmentation versus kyphoplasty. Eur Spine J, 2010. 19(6): p. 916-23.

37. Chang, X., et al., Vertebroplasty versus kyphoplasty in osteoporotic vertebral compression fracture: a metaanalysis of prospective comparative studies. Int Orthop, 2015. 39(3): p. 491-500.

38. Chen, C., et al., Comparing pain reduction following kyphoplasty and vertebroplasty : A meta-analysis of randomized and non-randomized controlled trials. Orthopade, 2017. 46(10): p. 855-863.

39. Landham, P.R., et al., Is kyphoplasty better than vertebroplasty at restoring form and function after severe vertebral wedge fractures? The Spine Journal, 2015. 15(4): p. 721-732.

40. Schofer, M.D., et al., Comparison of kyphoplasty and vertebroplasty in the treatment of fresh vertebral compression fractures. Arch Orthop Trauma Surg, 2009. 129(10): p. 1391-9.

41. Lee, M.J., et al., Percutaneous treatment of vertebral compression fractures: a meta-analysis of complications. Spine (Phila Pa 1976), 2009. 34(11): p. 1228-32.

42. Kumar, K., R. Nguyen, and S. Bishop, A comparative analysis of the results of vertebroplasty and kyphoplasty in osteoporotic vertebral compression fractures. Neurosurgery, 2010. 67(3 Suppl Operative): p. ons171-88; discussion ons 188 .

43. Bozkurt, M., et al., Comparative analysis of vertebroplasty and kyphoplasty for osteoporotic vertebral compression fractures. Asian Spine J, 2014. 8(1): p. 27-34.

44. Wardlaw, D., et al., Efficacy and safety of balloon kyphoplasty compared with non-surgical care for vertebral compression fracture (FREE): a randomised controlled trial. Lancet, 2009. 373(9668): p. 1016-24.

45. Stevenson, M., et al., Percutaneous vertebroplasty and percutaneous balloon kyphoplasty for the treatment of osteoporotic vertebral fractures: a systematic review and cost-effectiveness analysis. Health Technol Assess, 2014. 18(17): p. 1-290.

46. Svedbom, A., et al., Balloon kyphoplasty compared to vertebroplasty and nonsurgical management in patients hospitalised with acute osteoporotic vertebral compression fracture: a UK cost-effectiveness analysis. Osteoporos Int, 2013. 24(1): p. 355-67.

47. Lange, A., et al., Survival and cost comparison of kyphoplasty and percutaneous vertebroplasty using German claims data. Spine (Phila Pa 1976), 2014. 39(4): p. 318-26.

48. Guan, H., et al., Early or delayed operation, which is more optimal for kyphoplasty? A retrospective study on cement leakage during kyphoplasty. Injury, 2012. 43(10): p. 1698-1703.

49. Xie, L., et al., Percutaneous vertebroplasty versus conservative treatment for osteoporotic vertebral compression fractures: An updated meta-analysis of prospective randomized controlled trials. Int J Surg, 2017. 47: p. 25-32.

50. Percutaneous vertebroplasty for treatment of painful osteoporotic vertebral compression fractures: an evidencebased analysis. Ont Health Technol Assess Ser, 2010. 10(19): p. 1-45.

51. Hsieh, M.K., L.H. Chen, and W.J. Chen, Current concepts of percutaneous balloon kyphoplasty for the treatment of osteoporotic vertebral compression fractures: evidence-based review. Biomed J, 2013. 36(4): p. $154-61$. 